\title{
$O$ processo como instrumento do estado democrático de direito
}

\author{
Fernanda Heloisa Macedo Soares ${ }^{1}$ \\ Maiara Cristina Lima Massine ${ }^{2}$
}

\section{Resumo}

A presente pesquisa tem como objeto o estudo do processo enquanto instrumento do Estado Democrático de Direito, buscando relacionar o referido instituto jurídico ao modelo de Estado adotado pelo novo ordenamento jurídico inaugurado pela Constituição Federal de 1988. Assim, já em seu artigo $1^{\circ}$, a Constituição Federal constitui a República Federativa do Brasil em Estado Democrático de Direito, preocupado com uma organização estatal adequada e com um processo jurídico justo e célere, por assim dizer, efetivo. O processo possui um papel extremamente importante que é o de solucionar os conflitos e proporcionar a paz social na medida em que normatiza as relações interpessoais por meio das decisões que emanam dos tribunais. O texto consagrado pela Lei Maior também trata da importância do Fundamento Constitucional da Dignidade da Pessoa Humana e do Princípio Constitucional do Devido Processo Legal que devem ser observados pelo processo, pois estes servem como base para a construção do Estado proposto pela norma constitucional. O referido Estado deve estar comprometido com os valores sociais, políticos e jurídicos que também devem ser observados pelo processo enquanto ferramenta hábil para se alcançarem tais objetivos ligados ao bem comum. Em suma, a pesquisa procura abordar os meios necessários para se alcançar a efetividade do modelo estatal proposto pelo constituinte por meio do reconhecimento da instrumentalidade do processo, assim reconhecida como elemento integrante da própria justiça.

Palavras-chave: Processo. Estado democrático de direito. Instrumentalidade.

1 Mestranda em Direito pelo Centro Universitário Eurípides de Marília (UNIVEM). Bolsista pela Coordenação de Aperfeiçoamento de Pessoal de Nível Superior (CAPES).

2 Mestranda em Direito pelo Centro Universitário Eurípides de Marília (UNIVEM). Bolsista pela Coordenação de Aperfeiçoamento de Pessoal de Nível Superior (CAPES). 


\section{Introdução}

Os temas processo e democracia têm se mostrado bastante interessantes e pertinentes no panorama brasileiro atual, tanto é verdade que se tornou inconcebível pensar em qualquer assunto sem relacioná-lo à Carta Constitucional de 1988 e, consequentemente, ao Estado Democrático de Direito inaugurado por ela. Sendo assim, o presente trabalho tem como objeto de estudo a instrumentalidade do processo, na medida em que ele funciona como ferramenta dessa nova concepção de Estado descrita no artigo $1^{\circ}$ da atual Constituição Federal Brasileira.

Por meio de pesquisa bibliográfica sobre o tema, buscamos estabelecer conceitos e traçar conclusões acerca do escopo processual constitucional que se procura alcançar por meio do processo. Desse modo, primeiramente conceituaremos o termo processo para então adentrarmos a função que ele possui dentro da órbita social e jurídico-constitucional, visto que um dos papéis desempenhados pelo processo enquanto instrumento é o de pacificar os conflitos, restabelecendo a paz junto à sociedade.

Posteriormente, passaremos a um breve estudo do Estado Democrático de Direito, traçando para tanto o seu conceito junto à doutrina, bem como a sua relação com o Fundamento Constitucional da Dignidade da Pessoa Humana e com o Princípio Constitucional do Devido Processo Legal, ambos previstos na norma constitucional, pois entendemos que essa relação serve como base para sustentar o sistema em que se apoia o processo e os seus objetivos enquanto instrumento.

Por fim, adentraremos no foco central de nossa pesquisa que é a instrumentalidade do processo. Sendo que, para tanto, analisaremos os escopos sociais, políticos e jurídico que o cercam, além de constatarmos na prática como o Superior Tribunal de Justiça se utiliza do princípio da instrumentalidade processual em suas decisões para cumprir com os preceitos constitucionais, bem como atingir o objetivo da ordem democrática e de direito vigente em nosso Estado, qual seja, a paz social. 


\section{Processo}

\subsection{Conceito}

Segundo Francisco Wildo Lacerda Dantas, grande parte dos estudiosos afirmam que o termo processo tem origem na expressão em latim procedere, ou seja, um cair para frente, caminhar, seguir. Nesse sentido, conforme elucida Calmon de Passos citado pelo mesmo autor e de maneira inclusive redundante, o processo é um seguir para frente e não um voltar para trás, ${ }^{3}$ ele "é o conjunto de atos necessários à obtenção de uma providência jurisdicional, num determinado caso concreto". ${ }^{4}$

Ainda para Francisco Wildo Lacerda Dantas, "o processo é visto tanto como a atividade desenvolvida para o exercício da jurisdição quanto para a provocação dela - através da ação - para a prestação jurisdicional, que lhe constitui o objetivo final". ${ }^{5}$ Sem o processo a jurisdição não funciona.

O referido autor ainda transcreve em sua obra o conceito dado por Carnelutti sobre o que venha a ser processo, assim, para este, o processo "é um conjunto de atos dirigidos a formulação ou à aplicação dos mandatos jurídicos, cujo caráter consiste na elaboração a fim das pessoas interessadas (partes), com uma ou mais pessoas desinteressadas (juízes, ofício judicial)”. ${ }^{6}$

Para José Roberto dos Santos Bedaque, processo é a regulamentação do método de solução de conflitos que se dedica "a possibilitar que o resultado da atividade estatal contribua decisivamente para a manutenção da integridade do

3 DANTAS, Francisco Wildo Lacerda. Jurisdição, ação (defesa) e processo. São Paulo: Dialética, 1997. p. 137.

${ }^{4}$ DANTAS, Francisco Wildo Lacerda. Jurisdição, ação (defesa) e processo. São Paulo: Dialética, 1997. p. 148.

5 DANTAS, Francisco Wildo Lacerda. Jurisdição, ação (defesa) e processo. São Paulo: Dialética, 1997. p. 136.

${ }^{6}$ DANTAS, Francisco Wildo Lacerda. Jurisdição, ação (defesa) e processo. São Paulo: Dialética, 1997. p. 140. 
ordenamento jurídico, a eliminação dos litígios e a pacificação social". ' De forma objetiva, o autor coloca ainda que o processo "é simples método de solução de controvérsias, que se desenvolve sob a direção do juiz, segundo determinado procedimento, devendo assegurar às partes possibilidade de participação".

Cândido Rangel Dinamarco nos ensina que "o processo é instrumento predisposto ao exercício do poder e que este consiste na capacidade de decidir e impor decisões".

Elucida Calmon de Passos que ao processo se assegura o devido processo constitucional jurisdicional como sendo um complexo de garantias mínimas contra o subjetivismo e o arbítrio dos que têm o poder de decidir, exigindo-se dessa forma a prévia criação e definição da competência daqueles a quem se confere a capacidade de decidir a situação concreta, a bilateralidade da audiência, a publicidade, a fundamentação das decisões e o controle delas. Ao dispensar ou delimitar qualquer dessas garantias não se simplifica ou acelera o procedimento, pois só privilegia a efetividade da tutela, favorecendo o arbítrio em melhoria do desafogo do judiciário. "Favorece-se o poder, não os cidadãos, dilata-se o espaço dos governantes e restringe-se o dos governados." E isso, continua o autor, "se me afigura a mais escancarada anti-democracia que se pode imaginar." ${ }^{10}$

Em suma, "o processo é o método estatal de solução das crises verificadas no plano do direito material. Ao regulamentá-lo, o legislador procura estabelecer os meios destinados a possibilitar que esse instrumento atinja seu escopo maior, ${ }^{11} \mathrm{ou}$ seja, restabelecer a paz entre os particulares e, com isso, manter a da sociedade". ${ }^{12}$

7 BEDAQUE, José Roberto dos Santos. Efetividade do processo e a técnica processual. São Paulo: Malheiros, 2006. p. 18.

8 BEDAQUE, José Roberto dos Santos. Efetividade do processo e a técnica processual. São Paulo: Malheiros, 2006. p. 571.

9 DINAMARCO, Cândido Rangel. A instrumentalidade do processo. 6. ed. São Paulo: Malheiros, 1998. p. 179.

${ }^{10}$ PASSOS, Calmon J. J. Direito, poder, justiça e processo. Rio de Janeiro: Forense, 2000. p. 70.

${ }^{11}$ BEDAQUE, José Roberto dos Santos. Efetividade do processo e a técnica processual. São Paulo: Malheiros, 2006. p. 72.

12 THEODORO JÚNIOR, Humberto. Curso de direito processual civil. 38. ed. Rio de Janeiro: Forense, 2002. v. 1, p. 5. 


\subsection{O processo como instrumento de modificação no campo constitucional e legal ${ }^{13}$}

Mesmo não sendo atribuição do Poder Judiciário a criação ou modificação da norma em plano constitucional ou mesmo infraconstitucional em razão da adoção, no artigo $2^{\circ}$ da Constituição Federal, pelo sistema da Separação dos Poderes, que os separa em três órgãos distintos e harmônicos entre si, a interpretação que emana dos tribunais vem sendo apontada como ferramenta de modificação constitucional, pois no processo o Estado é a figura maior, pois cabe a ele resolver e dar respostas aos reclames da sociedade, uma vez que, na Constituição Federal estão elencados um rol de direitos os quais cabe ao Estado garantir.

As decisões prolatadas pelos órgãos do judiciário, além de possuírem imperatividade, também influenciam no teor da norma, bem como na sua interpretação. A deficiência de linguagem, as lacunas e as omissões que existem na Constituição e também as mudanças sociais, a evolução dos valores, entre outros fatores são apontados por constitucionalistas como fatores que conduzem à realidade ora abordada.

Nesse contexto, não há como não pensar na Constituição, no processo e no exercício de poder desempenhado pelo juiz como elementos que interagem entre si. A Constituição atua no processo quando lhe garante os princípios constitucionais fundamentais para o seu fiel cumprimento, visando, com isso, à aplicação dos preceitos e garantias por ela estabelecidos.

Já o poder do juiz figura nesse quadro como guardião da Constituição, na medida em que interpreta e cumpre o que nela vem estabelecido. Ou seja, o juiz funciona como um elo entre a Constituição e o processo, entre o Estado e a sociedade, pois as interpretações reiteradas feitas pelo judiciário muitas vezes geram a convicção do que vem estabelecido em seus conteúdos. Contudo, isso não quer dizer que tais decisões sejam fontes normativas ou constituam direitos.

13 DINAMARCO, Cândido Rangel. A instrumentalidade do processo. 6. ed. São Paulo: Malheiros, 1998. p. 39. 
O julgador possui independência que resulta e contribui para uma dinâmica normativa, bastando para isso que esse juiz independente não seja conservador, pois, se assim for, corre-se o risco de as interpretações progressistas serem rejeitas. $\mathrm{O}$ Poder Judiciário como todo Direito sofre influência do forte pensamento positivista vinculado exclusivamente a normas, e essa maneira de resolução de conflito acarretou decisões diversas da realidade, sem a devida preocupação com a efetivação da justiça, desde que fosse cumprida a lei em seu inteiro teor. Mas, atualmente, já se percebe uma mudança nessa maneira de pensar e com isso é trazido ao campo jurídico uma interpretação mais humanística na busca da solução de conflitos que busque combinar lei, realidade social com a satisfação das partes envolvidas no litígio.

Por meio dessa elucidação, podemos observar a função do processo enquanto instrumento de mudanças na ordem jurídica normativa, visto que as decisões emanadas dos tribunais podem gerar "pressões no legislador e sobre o próprio constituinte, no sentido de alterar textos do direito positivo. E isso [...] é legítima influência exercida sobre os indivíduos agentes do poder estatal". ${ }^{14}$

\section{Estado democrático de direito}

As crises de legitimação do modelo do Estado Social ocorridas ao final da Segunda Guerra Mundial geraram questionamentos que resultaram em inúmeras mudanças sociais, e, consequentemente, no Estado Democrático de Direito, ora atuante em nosso ordenamento jurídico. Assim, o Estado Democrático de Direito passou a valorizar os direitos individuais de liberdade, alterou os parâmetros de tratamento dos direitos e as garantias dos indivíduos e conservou a liberdade e a dignidade da pessoa humana como valores precípuos do ordenamento.

Cumpre ressaltar que o modelo do Estado Democrático de Direito preza, primeiramente, por bons operadores do direito, e não somente por boas leis como fazia o paradigma anterior. Nesse sentido, a sociedade passa a exigir uma desvin-

${ }^{14}$ DINAMARCO, Cândido Rangel. A instrumentalidade do processo. 6. ed. São Paulo: Malheiros, 1998. p. 43. 
culação do Estado com a lei estrita em favor de uma ligação efetiva com um direito que valorize a moral, a justiça e, sobretudo, a paz social. A mera declaração e o reconhecimento de um direito não mais satisfazem, é preciso garanti-lo acima de tudo.

\subsection{Conceito}

A atual Constituição Federal brasileira, logo em seu artigo 1, traz que "a República Federativa do Brasil [...] constitui-se em Estado Democrático de Direito". ${ }^{15}$ Diante desse contexto, cientistas políticos e juristas buscaram em vários aspectos a definição do que seja o Estado Democrático de Direito.

Assim, Loewenstein explica que "o aspecto principal do Estado Constitucional residiria na distribuição e nos mecanismos institucionais de controle do poder político. Fazendo com que este seja efetivamente submetido aos seus destinatários, ou seja, ao povo. O referido autor destaca ainda o papel da Constituição na formação da ordem fundamental estatal para alcançar o poder”. ${ }^{16}$

Contudo, mesmo o Estado Democrático de Direito sendo um fator de suma relevância, o controle do poder político se mostra extremamente insignificante para exteriorizá-lo.

Já Alexandre de Moraes define Estado Democrático de Direito como sendo “a exigência de reger-se por normas democráticas, com eleições livres, periódicas e pelo povo, bem como o respeito das autoridades públicas aos direitos e garantias fundamentais". ${ }^{17}$ Entretanto, ele não pode ser limitado somente a questões de

${ }^{15}$ BRASIL. Constituição (1988). Emenda Constitucional número 42, de 19 de dezembro 2003. Constituição da República Federativa do Brasil. 33. ed. São Paulo: Saraiva, 2004. p. 3.

${ }^{16}$ Apud SILVA, Enio Moraes da. O Estado democrático de direito. Disponível em: $<$ http://gravatai2.ulbra.tche.br/portal2007/cursos/graduacao/direito/professores/analucia-jaques-ramos/disciplinas/competencia-politica-social-e-juridica/Estado\%20 Democratico\%20de\%20Direito.pdf>. Acesso em: 08 de nov. 2008.

${ }^{17}$ MORAES, Alexandre de Moraes. Direito constitucional. 15. ed. São Paulo: Atlas, 2004. p. 53. 
representação política, pois democracia não se resume à forma da eleição, de escolha dos governantes pelos cidadãos, visto ser a democracia o sistema de governo que, além de admitir a participação de todos, tem a liberdade do ser humano como princípio fundamental. ${ }^{18}$

Enunciar o direito como democrático reclama o prévio de sua produção mediante um processo estruturado como tal, exigindo-se para tanto uma organização política adequada. Porém, aplicar o direito não exige somente a organização política apropriada da função jurisdicional, mas também o processo jurisdicional correspondente, entendido como sendo todo aquele que satisfaz as exigências de um Estado Democrático de Direito. Nota-se que o direito é decisão, pois em todos os seus pressupostos e fases, há o aspecto decisório, tornando-se um elemento constitutivo da dimensão democrática do Estado de Direito, uma garantia para o cidadão e um espaço real de liberdade e de sua efetiva autodeterminação, fatores indispensáveis para a autêntica cidadania.

Por fim, o Estado Democrático de Direito só é tido como tal quando os que são responsáveis pelo poder político o exercitam, respeitando as questões sociais, isto é, quando as entidades e os órgãos responsáveis pelo poder político se sujeitam ao controle fiscalizador recíproco, buscando uma atuação harmônica sem prejuízo da sua autonomia.

\subsection{Considerações acerca do conceito de princípios}

Princípios podem ser definidos como toda e qualquer estrutura sobre a qual se alicerça algo. Constituem caminhos fundamentais e amplos que apontam de onde devemos partir para a busca de algo, orientando acerca dos caminhos corretos a serem tomados quando das ecolhas. Por meio deles, é possível criar regras e normas de conduta.

${ }^{18}$ MOREIRA, Edson Fábio Garutti. Humanismo de Maritain e a burocracia. São Paulo: Loyola, 2001. p. 30. 
Segundo os ensinamentos de Celso Antonio Bandeira de Mello,

Princípio é, por definição, mandamento nuclear de um sistema, verdadeiro alicerce dele, disposição fundamental que se irradia sobre diferentes normas, compondo-lhes o espírito e servindo de critério para a sua exata compreensão e inteligência, exatamente por definir a lógica e a racionalidade do sistema normativo, no que lhe confere a tônica e lhe dá sentido harmônico. É o conhecimento dos princípios que preside a intelecção das diferentes partes componentes do todo unitário que há por nome sistema jurídico positivo. ${ }^{19}$

Portanto, no campo jurídico, os princípios podem ser classificados como o norte do ordenamento jurídico como um todo, sendo, portanto, muito mais amplo que o das regras, tanto que entre eles é admitido colisão, mas nunca conflito. O que implica dizer que eles não se excluem entre si. Assim, os princípios jurídicos são as estruturas do ordenamento que orientam para as diretrizes que devem servir de base para todo o direito.

\subsection{O estado democrático de direito e o princípio constitucional do devido processo legal}

O Estado Democrático de Direito brasileiro assegura, por meio da atual Constituição, o direito ao devido processo legal como sendo uma das essenciais garantias individuais. E é por essa garantia explícita feita ao devido processo legal ao longo do texto do artigo $5^{\circ}$, inciso LIV, que a atual Carta se difere das Constituições anteriores.

Para Araújo Cintra, Grinover e Dinamarco, o Princípio do Devido Processo Legal é formado por três outros princípios informativos ${ }^{20}$ integrantes do processo,

${ }^{19}$ MELLO, Celso Antonio Bandeira de. Curso de direito administrativo. 8. ed. São Paulo: Malheiros, 1996. p. 545.

20 A expressão princípios informativos é usada na medida em que entendemos que os mesmos representam, nas palavras de Cintra, Grinover e Dinamarco, uma aspiração de melhoria do aparelhamento processual. CINTRA, Antonio Carlos de Araújo; GRINOVER, Ada Pellegrini; DINAMARCO, Cândido Rangel Dinamarco. Teoria geral do processo. 19. ed. São Paulo: Malheiros, 2003. p. 50-51. 
que são o contraditório, a isonomia e a ampla defesa. ${ }^{21}$ Tais princípios asseguram os argumentos e fundamentos processuais, visto que permitem a participação direta das partes envolvidas e a proporcional igualdade entre elas.

É importante ressaltar a afirmação de Marcos Vinicius Rios Gonçalves, segundo o qual, o devido processo legal preserva as garantias e exigências do Estado Democrático de Direito, na mesma velocidade em que limita o exercício do Poder Judiciário. ${ }^{22}$ Assim, o Devido Processo Legal possui grande importância na preservação do Estado Democrático, pois proporciona às partes, seja em processo judicial, como em processo administrativo, o direito a todos os recursos próprios do contraditório e da ampla defesa.

O corolário da ampla defesa compreende todos os meios dados ao acusado que lhe permitam trazer ao processo as informações necessárias à apuração da verdade, bem como o direito de se omitir ou permanecer calado caso entenda conveniente. Já o contraditório "é a própria exteriorização da ampla defesa, impondo a condução dialética do processo", ${ }^{23}$ já que em relação a tudo o que for produzido pela acusação, é facultado à defesa a oportunidade de se opor.

Para Humberto Theodoro Júnior ${ }^{24}$ a garantia do Devido Processo Legal abarca algumas categorias fundamentais além do contraditório e da ampla defesa, como, por exemplo, a garantia do juiz natural, do acesso à justiça, entre outras. $\mathrm{O}$ referido autor afirma ainda que, atualmente, à ideia do devido processo legal se encontra intimamente ligada à ideia de processo justo.

${ }_{21}$ PEDRON, Flávio Quinaud; CAFFARATE, Viviane Machado. Apontamentos para uma compreensão adequada do processo no Estado Democrático de Direito. Jus Navigandi, Teresina, v. 7, n. 118, 30 out. 2003. Disponível em: <http://jus2.uol.com.br/doutrina/ texto.asp?id=4317>. Acesso em: 05 nov. 2008.

22 GONÇALVES, Marcus Vinicios Rios. Novo curso de direito processual civil. São Paulo: Saraiva, 2004, v.1, p. 36.

23 MORAES, Alexandre de Moraes. Direito constitucional. 15. ed. São Paulo: Atlas, 2004. p. 125.

${ }^{24}$ THEODORO JUNIOR, Humberto. Curso de direito processual civil. 38. ed, Rio de Janeiro: Forense, v. 1, 2002. p. 23. 
Entende Nelson Nery Junior que "bastaria a norma constitucional haver adotado o princípio do 'due process of law' para que daí decorressem todas as consequências processuais que garantiriam aos litigantes o direito a um processo e uma sentença justa." Afirmando ainda que o devido processo legal é "o gênero do qual todos os demais princípios constitucionais são espécies". ${ }^{25}$

Portanto, atualmente não é possível falar em Estado Democrático de Direito sem automaticamente pensar no Princípio do Devido Processo Legal como sendo propulsor, fundamento e garantia dele. Em suma, o direito ao processo (entendido não como simples realização de atos) na ótica do Estado Democrático de Direito pressupõe a garantia ao próprio Princípio do Devido Processo Legal.

\subsection{0 estado democrático de direito e o fundamento constitucional da dignidade da pessoa humana}

A Constituição Federal inaugurou um novo paradigma ao afirmar, no inciso III do seu artigo $1^{\circ}$, que a República Federativa do Brasil constitui-se em Estado Democrático de Direito e tem como um de seus fundamentos a Dignidade da Pessoa Humana.

Classificada como princípio-fundamento por parte da doutrina o Fundamento da Dignidade da Pessoa Humana, além de tutelar direitos individuais, funciona também como alicerce da República Federativa do Brasil.

Pode-se dizer que, como princípio e valor fundamental, a Dignidade da Pessoa Humana é o que sustenta e justifica o próprio ordenamento jurídico, o que consente com a sua caracterização como Princípio Constitucional de maior valor dentro das relações jurídicas e humanas.

${ }^{25}$ NERY JUNIOR, Nelson. Princípios do processo civil na Constituição Federal. 3. ed., rev. São Paulo: Revista dos Tribunais, 1996. p. 30. 
A Dignidade da Pessoa Humana é essencial às personalidades humanas e concede uniformidade aos direitos e garantias fundamentais. "Esse fundamento afasta a idéia de predomínio das concepções transpessoalistas de Estado e Nação, em detrimento da liberdade individual." ${ }^{26}$ Ou seja, com a dignidade o indivíduo passa a ser o limite e o fundamento do domínio político da República, como ensina Canotilho citado em nota de rodapé por Celso Antônio Pacheco Fiorillo. ${ }^{27}$

Segundo Rizzatto Nunes, citado pelo mesmo autor, a dignidade da pessoa humana é o "primeiro fundamento de todo o sistema constitucional posto e o último arcabouço da guarida dos direitos individuais". ${ }^{28}$

Dessa forma, pode-se afirmar que, com o advento da Constituição Federal de 1988, o ser humano passou a ser o fundamento e objetivo maior do sistema jurídico brasileiro. Qualquer que seja a questão, o indivíduo deve ser o escopo final da discussão, ou seja, em matéria social, política ou mesmo jurídica deve ser analisado o homem em consonância com o Fundamento Constitucional da Dignidade da Pessoa Humana para que se legitime o Estado Democrático de Direito.

\section{A instrumentalidade do processo}

Para que o Estado Democrático de Direito cumpra com os papéis que lhe são devidos, é preciso que o sistema processual seja válido, eficaz, conferindo segurança e justiça às partes e à sociedade como um todo.Essas referidas características são alcançadas por meio de instrumentos que asseguram a sua real aplicação. Tais instrumentos podem ser sintetizados nos princípios presentes na Constituição Federal, visto que eles conduzem a um fim justo, ao menos do ponto de vista teórico, já que garantem aos litigantes o direito de contradizerem o que foi alegado pela parte contrária, bem como de se defenderem por todos os meios lícitos existentes,

\footnotetext{
${ }^{26}$ MORAES, Alexandre de Moraes. Direito constitucional. 15. ed. São Paulo: Atlas, 2004. p. 54.

${ }^{27}$ FIORILLO, Celso Antônio Pacheco. Princípios do processo ambiental. São Paulo: Saraiva, 2004. p. 11-12.

${ }^{28}$ FIORILLO, Celso Antônio Pacheco. Princípios do processo ambiental. São Paulo: Saraiva, 2004. p. 11.
} 
de serem tratados de forma igualitária, de serem julgados por um juiz previamente constituído, entre outros.

Suzana J. de Oliveira Carmo, ao citar Franz Kafka, afirma que "as funções exercidas pelo Estado só se justificam em prol da sociedade," ${ }^{29}$ portanto, não é válido um processo que desumaniza o homem. Kafka destaca de forma incisiva o tripé: "necessidade, finalidade e utilidade, presentes na instrumentalidade jurisdicional, como expressão de uma razão processual," e, sugere que "a ausência de qualquer desses elementos, romperia o nexo necessário à sua propositura ou desempenho" ${ }^{30}$

Dessa forma, o processo dentro do Estado Democrático de Direito precisa ser conduzido de maneira a ser justo e, consequentemente, efetivar as garantias positivadas na norma constitucional em prol do próprio indivíduo.

\subsection{Posição doutrinária}

A instrumentalidade do processo se liga ao sistema processual em razão do enfoque social e político que possui dentro da ordem jurídica.

Assim, para Francisco Wildo Lacerda Dantas, a instrumentalidade do processo é “a técnica que visa torná-lo um instrumento ágil e rápido à prestação jurisdicional assegurando um justo processo - fair process - para a certificação e a realização do direito nele conhecido, visando, sobretudo, a pacificação social"."

Ensinam Araújo Cintra, Grinover e Dinamarco que "em última análise, o processo não é apenas instrumento técnico, mas sobretudo ético [...] é profun-

29 OLIVEIRA, Suzana J. de. A função judicante do Estado e a real utilidade do instrumento processual. Disponível em: <http://br.monografias.com/trabalhos909/a-funcao-judicante/ a-funcao-judicante.shtml> Acesso em: 6 nov 2008.

30 OLIVEIRA, Suzana J. de. A função judicante do Estado e a real utilidade do instrumento processual. Disponível em: http://br.monografias.com/trabalhos909/a-funcao-judicante/ a-funcao-judicante.shtml. Acesso em: 6 nov. 2008.

31 DANTAS, Francisco Wildo Lacerda. Jurisdição, ação (defesa) e processo. São Paulo: Dialética, 1997. p. 233. 
damente influenciado por fatores históricos, sociológicos e políticos".32 Portanto, quando se fala na instrumentalidade do processo, não se refere somente à ligação que ele possui a norma material. ${ }^{33}$

Afirmam ainda que toda atividade jurídica que emana do Estado possui um escopo maior de pacificação social. Dessa maneira, o Estado fundamentalmente visa evitar ou eliminar os conflitos existentes na sociedade por meio de decisões justas, e, consequentemente, fazendo justiça. Dentro desse contexto, o processo atua como um "instrumento a serviço da paz social". ${ }^{4}$

Nesse sentido, Luiz Guilherme Marinoni sustenta que o processo baseado em decisão ilegítima, "ou que não se estruture a propiciar uma decisão legítima," não pode ser entendido como instrumento do Estado Democrático de Direito.

O processo se encontra intimamente ligado aos valores históricos do momento em que ele é exteriorizado. Sendo que, entender o processo unicamente como instrumento de aplicação da lei por parte do Estado somente é aceitável se considerarmos o período do Estado Liberal, no qual o juiz era proibido de se posicionar ao longo do processo, de interpretar a norma, chegando a ser chamado de a boca da lei (bouche de loi). ${ }^{36}$

Assim, de mero meio de aplicação da lei, o processo passou a ser um instrumento de proteção dos direitos fundamentais, principalmente no que tange ao

${ }^{32}$ CINTRA, Antonio Carlos de Araújo; GRINOVER, Ada Pellegrini; DINAMARCO, Cândido Rangel Dinamarco. Teoria geral do processo. 19. ed. São Paulo: Malheiros, 2003. p. 79.

${ }^{33}$ CINTRA, Antonio Carlos de Araújo; GRINOVER, Ada Pellegrini; DINAMARCO, Cândido Rangel Dinamarco. Teoria geral do processo. 19. ed. São Paulo: Malheiros, 2003. p. 41.

${ }^{34}$ CINTRA, Antonio Carlos de Araújo; GRINOVER, Ada Pellegrini; DINAMARCO, Cândido Rangel Dinamarco. Teoria geral do processo. 19. ed. São Paulo: Malheiros, 2003. p. 41.

${ }^{35}$ MARINONI, Luiz Guilherme. Teoria geral do processo. 3. ed. rev. e atual. São Paulo: Revista dos Tribunais, 2008. p. 400-401.

${ }^{36}$ MARINONI, Luiz Guilherme. Teoria geral do processo. 3. ed., rev. e atual. São Paulo: Revista dos Tribunais, 2008. p. 414 
Princípio da Dignidade da Pessoa Humana. Tanto que, como já abordado, a Dignidade da Pessoa Humana constitui um dos fundamentos da República Federativa do Brasil, assegurado pela Constituição Federal de 1988, ou seja, o Estado Constitucional determina uma interpretação processual à luz dos direitos fundamentais para que o processo atinja seu fim maior, qual seja, a paz social alcançada por meio da justiça.

Nesse mesmo caminho, ensina Marcos Vinicius Rios Gonçalves que "o processo não é um bem a que se aspira por si mesmo, mas um meio de obter a solução dos conflitos de interesses e a pacificação social". ${ }^{37}$

Importante ressaltar que, para Calmon de Passos, o processo, no âmbito jurídico, não se opera como simples meio ou instrumento, mas sim como elemento integrante do próprio direito. Assim, "a relação entre o chamado direito material e o processo não é uma relação meio/fim, instrumental, como se tem proclamado com tanta ênfase, ultimamente, por força do prestígio de seus arautos, sim uma relação integrativa, orgânica, substancial". ${ }^{38}$ Portanto, para esse autor, o processo não é algo que se opera como instrumento, mas sim algo que integra o próprio ser do direito. A relação entre direito material e processo não é simplesmente instrumental, porém integrativa.

Afirma Frederico Marques ${ }^{39}$ que o processo é "o instrumento iminente à jurisdição para que o Estado alcance” a composição do litígio.

Dessa forma, na medida em que o processo zela pela observação dos direitos e garantias fundamentais constitucionalmente garantidos ao homem, ele permite que o Estado se paute na e pela democracia, , sendo o instrumento desse poder eminentemente democrático.

${ }^{37}$ GONÇALVES, Marcus Vinicios Rios. Novo curso de direito processual civil. São Paulo: Saraiva, 2004. v. 1. p. 5.

${ }^{38}$ PASSOS, Calmon J. J. Direito, poder, justiça e processo. Rio de Janeiro: Forense, 2000. p. 68.

39 Apud DANTAS, Francisco Wildo Lacerda. Jurisdição, ação (defesa) e processo. São Paulo: Dialética, 1997. p. 136. 
Logo, é possível entender o processo como instrumento do Estado Democrático de Direito, desde que ele esteja pautado na justiça e, dessa forma, seja capaz de produzir a paz social, bem como garanta o acesso efetivo à justiça e respeite os fundamentos e princípios processuais constitucionais, principalmente o Fundamento da Dignidade da Pessoa Humana e o Princípio do Devido Processo Legal. Enfim, tratar o processo como instrumento do Estado Constitucional pressupõe que ele atinja os escopos sociais, políticos e jurídicos (que serão abordados no próximo subitem), e assim haja uma democracia de fato.

Araújo Cintra, Grinover e Dinamarco explicam que "falar em instrumentalidade [...], pois, é alertar para a necessidade efetiva do processo, ou seja, para a necessidade de ter-se um sistema processual capaz de servir de eficiente caminho à 'ordem jurídica justa”" 40

Desse modo, é inviável afirmar que o processo é um instrumento, se tal afirmativa não busca atingir o fim desejado, ou seja, todo instrumento é um meio, um caminho que só é válido quando cumpre a finalidade a que se propôs. Ou seja, o processo somente pode ser considerado instrumento do Estado Democrático de Direito desde que garanta e cumpra a própria razão desse Estado, alcançando o seu objetivo de pacificação social.

\subsection{Escopos sociais, políticos e jurídico do processo}

Para Araújo Cintra, Grinover e Dinamarco, ${ }^{41}$ não há como desvincular o processo do mundo social moderno, e, consequentemente, de três objetivos buscados pelo Estado por meio dele e da jurisdição. Tais objetivos são classificados pelos autores como sendo os objetivos sociais, os políticos e o jurídico, e o consequente

\footnotetext{
${ }^{40}$ CINTRA, Antonio Carlos de Araújo; GRINOVER, Ada Pellegrini; DINAMARCO, Cândido Rangel Dinamarco. Teoria geral do processo. 19. ed. São Paulo: Malheiros, 2003. p. 41.

${ }^{41}$ CINTRA, Antonio Carlos de Araújo; GRINOVER, Ada Pellegrini; DINAMARCO, Cândido Rangel Dinamarco. Teoria geral do processo. 19. ed. São Paulo: Malheiros, 2003. p. 41.
} 
entendimento deles se faz necessário para a compreensão da instrumentalidade do processo.

Para Cândido Rangel Dinamarco, "fixar os escopos do processo equivale, ainda, a revelar o grau de sua utilidade. [...] em outras palavras: a perspectiva instrumentalista do processo é teleológica por definição e o método teleológico conduz invariavelmente à visão do processo como instrumento predisposto à realização dos objetivos eleitos" ${ }^{42}$

Ainda salienta que “a jurisdição não tem um escopo, mas escopos (plural); é muito pobre a fixação de um escopo exclusivamente jurídico, pois o que há de mais importante é a destinação social e política do exercício da jurisdição. Ela tem, na realidade, escopos sociais (pacificação com justiça, educação), políticos (liberdade, participação, afirmação da autoridade do Estado e do seu ordenamento) e jurídico (atuação da vontade concreta do direito)".43

Passemos ao estudo de cada um dos escopos acima elencados.

\subsubsection{Escopos sociais}

O fim para o qual o Estado foi criado é o de organizar a vida em sociedade, dando condições para que cada indivíduo pertencente ao grupo realize seus desejos. Ou seja, se espera que o "Estado chegue efetivamente aos resultados propostos, influenciando favoravelmente a vida do grupo e de cada um de seus componentes". ${ }^{44}$

Com isso, tendo a jurisdição como manifestação do poder político, tem-se

42 DINAMARCO, Cândido Rangel. A instrumentalidade do processo. 6. ed. São Paulo: Malheiros, 1998. p. 149-150.

${ }^{43}$ DINAMARCO, Cândido Rangel. A instrumentalidade do processo. 6. ed. São Paulo: Malheiros, 1998. p. 387.

${ }^{44}$ DINAMARCO, Cândido Rangel. A instrumentalidade do processo. 6. ed. São Paulo: Malheiros, 1998 p. 159. 
que, mais do que a aplicação da justiça em um caso concreto, ela se mostra como meio para chegar à paz social. Assim, o direito e o processo estão voltados à pacificação dos conflitos existentes na sociedade, já que a atuação do direito se serve do processo, ou seja, ambos são "benefícios a serem prestados à sociedade". ${ }^{45}$

Nesse contexto, afirma Cândido Rangel Dinamarco, em que “a vida em sociedade gera insatisfações" ${ }^{46}$ o Estado tem por obrigação dar fim a essas insatisfações da população, buscando a reparação dos danos sofridos e, consequentemente, eliminá-las, mostrando dessa forma a sua legitimidade.

Por meio das leis e da jurisdição, ou seja, da positivação de seu poder, o Estado oferece esperança à sociedade de ver seus conflitos e insatisfações resolvidos, e com isso favorecer um ambiente propício à paz social.

Contudo, é importante para o efetivo papel pacificador do Estado que as decisões tomadas para a eliminação dos conflitos sejam aceitas pelas partes, e que cumulado a essas decisões, encontre-se o valor de justiça, ou seja, a eliminação dos conflitos deve se dar de forma justa, equitativa, gerando segurança jurídica.

Outra função social do Estado é informar e educar os indivíduos da sociedade acerca de seus direitos e obrigações, pois a tendência dos que confiam no Judiciário é cuidar dos seus próprios direitos, bem como dos direitos dos outros, resultando em mais responsabilidade e confiança.

Segundo José Roberto dos Santos Bedaque, ${ }^{47}$ a Constituição Federal assegura muito mais do que a mera formulação de pedido ao Poder Judiciário, vez que assegura um acesso efetivo à ordem jurídica justa.

45 DINAMARCO, Cândido Rangel. A instrumentalidade do processo. 6. ed. São Paulo: Malheiros, 1998 p. 160.

46 DINAMARCO, Cândido Rangel. A instrumentalidade do processo. 6. ed. São Paulo: Malheiros, 1998. p. 160.

${ }^{47}$ BEDAQUE, José Roberto dos Santos. Efetividade do processo e a técnica processual. São Paulo: Malheiros, 2006. p. 61-101. 
A falta de mecanismos que favoreçam o acesso ao Judiciário resulta em insatisfações e decepções permanentes, uma vez que aqueles que se veem lesados não se animam em procurar a justiça para verem seus conflitos solucionados. Tal situação de escassa infraestrutura social se mostra perigosa na medida em que um grande número de pessoas insatisfeitas pode originar manifestações violentas, hostis e agressivas.

Pode-se afirmar que a ideia do acesso à justiça constitui a síntese do pensamento instrumentalista, colocando em destaque a prestação de uma tutela jurisdicional ágil e de maior utilidade, discutindo sempre a questão do amplo e irrestrito acesso à justiça. Mas temos que ponderar que não basta garantir o direito de ação, havendo a necessidade de garantir o acesso a uma tutela jurisdicional justa, efetiva. O direito à tutela jurisdicional, como garantia constitucional, tem que, necessariamente, significar o direito a uma tutela efetiva, o que somente se torna possível se houver instrumentos adequados para alcançar os resultados pretendidos por aquele que demanda. Isso porque não basta simplesmente dizer que é garantido aos cidadãos o acesso à justiça, se ela não for justa e eficaz. Não se pode negar que isso está diretamente relacionado com o tempo de duração do processo. Difícil não é garantir, em relação aos órgãos jurisdicionais estatais, a porta de entrada, mas a porta de saída, com uma solução justa e célere.

Cândido Rangel Dinamarco elucida o caso do povo brasileiro como sendo pouco acostumado a recorrer ao Poder Judiciário devido à falta de informação e descrença no próprio sistema. Para resolver referido cenário e restituir a confiança da população, criaram-se os Juizados Especiais e o Código de Defesa do Consumidor, entendidos como instrumentos práticos e eficazes para solucionar as questões contenciosas.

Assim, a educação é um objetivo instrumental do processo, pois visa informar a população e, consequentemente, atraí-la para resolver seus descontentamentos junto ao Judiciário e levar à pacificação social.

É bom ressaltar que, embora algumas justiças especializadas brasileiras estejam comprometidas com o resultado do processo, não é percebido, na prática, 
que tal fato tem mudado a panorâmica da morosidade do judiciário, em especial, o da justiça comum. A demora na prestação da tutela, sem dúvida, representa uma das principais ameaças da efetividade do processo.

Além das causas internas ao Poder Judiciário, como a falta de servidores, não se pode esquecer o crescente volume de demandas hoje ajuizadas. O cidadão, mais consciente de seu direito, provoca mais atuação da função jurisdicional do que outrora. Com a onda do acesso formal à justiça, isto é, com a implementação de mecanismos facilitadores do ingresso em juízo, a comunidade passou a demandar mais.

José Roberto dos Santos Bedaque ${ }^{48}$ salienta que "a propósito da verdadeira cruzada em prol da celeridade do processo - nova obsessão de alguns - é preciso ser cauteloso, pois há risco de que outro valor extremamente importante acabe relegado segundo plano. Tão importante quanto acabar com a morosidade excessiva é preservar a segurança proporcionada pelo devido processo legal. Temos de - e esta é a nossa principal missão - encontrar o ponto de equilíbrio entre ambos".

Em suma, sob o aspecto social, o processo, além de ser capaz de cumprir com o seu compromisso, deve ser eficaz ao cumpri-lo. O que implica dizer que o aspecto social da instrumentalidade do processo se caracteriza com a apresentação das insatisfações em juízo, para consequentes soluções práticas e eficazes delas. .

\subsubsection{Escopos políticos}

A política está inserida no Estado fazendo com que exista uma ligação entre ela e o sistema processual, bem como a necessidade de se definir como se dá esta influência do processo com a política, entendida como sendo parte da Justiça.

\footnotetext{
${ }^{48}$ BEDAQUE, José Roberto dos Santos. Efetividade do processo e a técnica processual. São Paulo: Malheiros, 2006. p. 48.
} 
Cândido Rangel Dinamarco ${ }^{49}$ aborda três fatores essenciais dessa ligação entre processo e política. O primeiro é a necessidade do Estado em firmar seu poder de forma imperativa, forçosa, como forma de sustentar e cumprir a finalidade pela qual ele se legitima. O segundo aspecto é restringir a liberdade, ressalvando "os contornos do poder e do seu exercício, para a dignidade dos indivíduos as quais ele se exerce." Por fim, há a necessidade de garantir a presença da sociedade, de forma pessoal ou por meio de associações, nas decisões políticas do Estado, pois, por meio da jurisdição, o Estado busca integrar o elemento poder (no sentido de autoridade), com o elemento liberdade, tendo a participação da sociedade como valor democrático apto a conferir validade ao processo político. Ou seja, "a função jurisdicional tem a missão institucionalizada de promover a efetividade desses três valores fundamentais no Estado e na democracia, para a estabilidade das instituições”.

É inegável a utilização do processo pelo Estado para se atingirem os fins políticos abarcados pela norma, e dessa forma se constituir instrumento estatal de ação política. O processo ajuda na organização e na existência do Estado mediante o poder legítimo realizado por meios legítimos..$^{50}$ Além do mais, ao decidir e impor as suas decisões, o Estado confirma imperativamente o seu poder, idealizando a sociedade política mediante o processo e a jurisdição.

Outro objetivo político do processo é a preservação da liberdade pública, entendida dessa forma, pois, independentemente do objeto de tal liberdade, há a interferência do Poder Público para a consagração de um direito já positivado pela norma. Assim, todos os meios que o indivíduo e a sociedade possuem para influenciar o Poder são formas de praticar democracia, não sendo o voto o único meio de participação popular.

Dessa forma, temos a ação popular e os processos relativos ao meio ambiente como institutos da chamada Jurisdição Constitucional das Liberdades, pois são meios aptos a assegurar as garantias apresentadas na Lei Maior a título de par-

${ }^{49}$ DINAMARCO, Cândido Rangel. A instrumentalidade do processo. 6. ed. São Paulo: Malheiros, 1998. p. 168.

${ }^{50}$ DINAMARCO, Cândido Rangel. A instrumentalidade do processo. 6. ed. São Paulo: Malheiros, 1998. p. 169-170. 
ticipação democrática, conectando o processo à Constituição e à ordem política nela estabelecida, e influenciando, portanto, no destino político da sociedade. Este também é o caso do Habeas Corpus e do Mandado de Segurança, que mostram a evolução do ordenamento jurídico no sentido de oferecer uma estrutura processual que coloca em prática esses instrumentos constitucionais.

\subsubsection{Escopo jurídico}

Tratar o processo enquanto escopo jurídico sem considerar os aspectos sociais e políticos, ou seja, somente sob o seu aspecto instrumental ao direito material objetivo, mostra-se insuficiente para a ótica atual de um tempo solidarista e fraternal. A visão estritamente jurídica do processo representa seu segundo momento histórico, "consistente na afirmação da autonomia conceitual e metodológica e aprimoramento interno do sistema". ${ }^{51}$

A técnica processual possui grande relevância em razão da maneira como o processo e seus resultados são exteriorizados no mundo jurídico, pois esclarece a função que ele exerce diante do direito e da vida dos direitos. Portanto, o estudo do escopo jurídico nos leva a entender a forma do processo, bem como a sua posição no sistema jurídico.

A definição do escopo jurídico se mostra relevante perante a oposição entre a teoria dualista e a teoria unitária, pois com isso é possível demonstrar o momento em que o processo é admitido no mundo jurídico, bem como o modo como ele auxilia o direito.

Para a teoria dualista o direito material possui um "sistema suficiente em si mesmo para a criação de direitos e obrigações logo ao suceder de fatos relevantes". Enquanto para a teoria unitária o direito "não tem toda essa aptidão, participando

${ }^{51}$ DINAMARCO, Cândido Rangel. A instrumentalidade do processo. 6. ed. São Paulo: Malheiros, 1998. p. 177. 
então o processo do inter criativo". ${ }^{52}$ Segundo Cândido Rangel Dinamarco, , dependendo de qual teoria é adotada, além da maneira como o direito substancial é visto, escolhe-se também a função que o processo exerce perante esse direito, bem como o momento em que o sistema processual se insere no mundo jurídico como dito anteriormente.

O direito e o processo vivem em uma espécie de simbiose, primeiro, porque o processo é regido por normas de direito (normas estas que dizem como se dá a jurisdição e como se atinge o processo), segundo, porque o processo é ferramenta a serviço do direito, entendido, nesse caso, como o conjunto de normas e princípios.

Ocorre ainda que os juristas (juízes, legisladores etc.) possuem mais facilidade em trabalhar com técnicas positivadas em forma de leis abstratas e escritas do que valorar escopos sociais ou políticos. "O zelo por não errar nos julgamentos, especialmente em matéria de fato, é uma característica marcante dessa postura tradicional, herdeira de um culto exagerado à verdade e à certeza." ${ }^{53}$ Contudo, enquanto esse apego à certeza e à verdade for mantido, o aperfeiçoamento técnico do processo corresponderá a uma introspecção do sistema que deixa de questionar por que, como e para que o processo deve ser feito.

Não há dúvidas de que o escopo jurídico do processo é o que mais "se presta a considerações de ordem técnica e mais influências projeta sobre a técnica processual". ${ }^{44}$ Mas isso não autoriza conceituar o processo sob o enfoque puramente técnico, sem considerar fatores sociais, éticos e axiológicos, entre outros. Ou seja, não basta a preocupação somente com a prática do direito material e a estrutura interna do processo como, por exemplo, as técnicas de endereçamento do processo civil; é preciso considerar a pacificação social como motor de toda a razão que justifica a existência do sistema jurídico processual.

${ }^{52}$ DINAMARCO, Cândido Rangel. A instrumentalidade do processo. 6. ed. São Paulo: Malheiros, 1998. p. 189.

${ }^{53}$ DINAMARCO, Cândido Rangel. A instrumentalidade do processo. 6. ed. São Paulo: Malheiros, 1998. p. 221.

${ }^{54}$ DINAMARCO, Cândido Rangel. A instrumentalidade do processo. 6. ed. São Paulo: Malheiros, 1998. p. 219. 


\subsection{A instrumentalidade e seu sentido duplo: aspectos negativos e positivos}

A instrumentalidade do processo possui aspectos positivos e negativos que a ligam aos escopos processuais anteriormente definidos, pois, conforme ensina Cândido Rangel Dinamarco, tal ligação faz com que o processo "não deixe de ser instrumento do direito material (aspecto negativo)," bem como não deixe de ser "instrumento a serviço de vários objetivos, seja tanto quanto possível apto a realizá-los (aspectos positivos)." ${ }^{\prime 5}$

Como aspecto positivo da instrumentalidade do processo, Araújo Cintra, Grinover e Dinamarco elencam a "relação que liga o sistema processual à ordem jurídico-material e ao mundo das pessoas e do Estado". ${ }^{56}$ Nesse sentido positivo, é preciso a efetividade do sistema processual para atingir uma ordem jurídica que seja realmente justa. E para que a instrumentalidade efetive os aspectos positivos ora abordados, é necessário conhecer o fim almejado, bem como ultrapassar as barreiras econômicas e jurídicas existentes que muitas vezes dificultam o acesso à justiça. Ao abordarem o aspecto negativo da instrumentalidade, os referidos autores alertam "para o fato de que ele não é um fim em si mesmo e não deve, na prática cotidiana, ser guinado à fonte geradora de direitos. Os sucessos do processo não devem ser tais que superem ou contrariem os desígnios do direito material, do qual ele também é um instrumento".57

Instrui Eduardo Cambi ${ }^{58}$ que a instrumentalidade, vista pelo seu lado negativo, "pretende combater o formalismo (isto é, sem tornar o processo um conjunto de armadilhas ardilosamente preparadas pela parte mais astuciosa em detrimento

\footnotetext{
${ }^{55}$ DINAMARCO, Cândido Rangel. A instrumentalidade do processo. 6. ed. São Paulo: Malheiros, 1998. p. 267.

${ }^{56}$ CINTRA, Antonio Carlos de Araújo; GRINOVER, Ada Pellegrini; DINAMARCO, Cândido Rangel Dinamarco. Teoria geral do processo. 19. ed. São Paulo: Malheiros, 2003. p. 41.

${ }^{57}$ CINTRA, Antonio Carlos de Araújo; GRINOVER, Ada Pellegrini; DINAMARCO, Cândido Rangel Dinamarco. Teoria geral do processo. 19. ed. São Paulo: Malheiros, 2003. p. 41-42.

${ }^{58}$ CAMBI, Eduardo. Neoconstitucionalismo e neoprocessualismo. Disponível em: <http:// www.panoptica.org/fevereiro2007pdf/1Neoconstitucionalismoeneoprocessu alismo.pdf> Acesso em: 19 nov. 2008.
} 
da mais incauta), capaz de menosprezar o caráter instrumental [...] mas, ao mesmo tempo, sem cair em um alternativismo destrambelhado, capaz de produzir a insegurança jurídica”. E, no que se refere ao seu caráter positivo, o processo deve ser capaz de produzir os objetivos sociais, políticos e jurídico a que se propõe em relação ao acesso à justiça "como o Juizado Especial Cível, a efetiva ampliação das defensorias públicas e a consolidação do papel do Ministério Público na defesa de interesses individuais homogêneos, coletivos e difusos" ao modo de ser do processo "que abrange dinâmica relação entre as partes, entre elas e o juiz, bem como entre o juiz e o processo; a plenitude e a restrição das garantias processuais, dentro do contexto do princípio da proporcionalidade; a elaboração de procedimentos diferenciados à tutela dos direitos materiais etc.," a justiça das decisões "seja pela utilização de um procedimento válido e justo para se chegar a decisão, seja pela reconstrução fiel dos fatos relevantes para a causa, seja ainda pela adequada interpretação das regras e princípios aplicáveis ao caso concreto" e a efetividade delas, "envolvendo temas como a melhor distribuição do ônus do tempo do processo entre as partes, a ampliação das sentenças mandamentais e executivas lato sensu, a concretização dos provimentos urgentes baseados em cognição sumária, o abandono da rígida separação entre cognição e execução, a desmitificação da verdade processual "obtida” formalmente com a coisa julgada etc.”

Em suma, Cândido Rangel Dinamarco articula que o viés negativo da instrumentalidade processual reside nas limitações funcionais do próprio sistema processual, pois o processo "não é um fim em si mesmo e, portanto as suas regras não têm valor absoluto que sobrepuje as do direito substancial e as exigências sociais de pacificação de conflitos e conflitantes". ${ }^{59}$ Já o aspecto positivo está ligado à efetividade do processo, na medida em que ele esgota "os objetivos que o legitimam no contexto jurídico-social e político" ${ }^{60}$ o que implica dizer que, positivamente, a instrumentalidade se caracteriza pela apresentação das insatisfações e consequente solução justa obtida por meio dos seus escopos institucionais.

${ }^{59}$ DINAMARCO, Cândido Rangel. A instrumentalidade do processo. 6. ed. São Paulo: Malheiros, 1998. p. 266.

${ }^{60}$ DINAMARCO, Cândido Rangel. A instrumentalidade do processo. 6. ed. São Paulo: Malheiros, 1998. p. 266. 


\title{
4.4 A instrumentalidade segundo a jurisprudência do superior tribunal de justiça
}

O princípio da instrumentalidade do processo é constantemente invocado nos julgamentos para garantir a observação dos preceitos constitucionais, como por exemplo, o preceito da celeridade, ou mesmo o da economia processual, haja vista, não raras vezes, as partes se valerem de subterfúgios processuais para tentarem driblar a justiça ou mesmo ganhar tempo durante a tramitação do processo, devido às mais variadas razões.

\begin{abstract}
AgRg no Ag 678474 / RJ. AGRAVO REGIMENTAL NO AGRAVO DE INSTRUMENTO. 2005/0073501-0. Processo civil. Agravo no agravo de instrumento. Denunciação da lide. Princípios da celeridade e da instrumentalidade do processo. Embargos de declaração. Ausência de omissão, contradição ou obscuridade. Prequestionamento. Dissenso pretoriano. Não comprovação. - Não deve ser anulado o processo, em detrimento dos princípios da celeridade e da instrumentalidade do processo, para permitir a denunciação da lide, uma vez que não há prejuízo para litisdenunciante que poderá exercer o seu direito de regresso em ação própria. Precedentes. - Rejeitam-se os embargos de declaração quando ausente omissão, contradição ou obscuridade a ser sanada. - O prequestionamento dos dispositivos legais tidos como violados constitui requisito de admissibilidade do recurso especial. Agravo no agravo de instrumento não provido. $^{61}$
\end{abstract}

Dentre os julgados analisados, notamos que o princípio da instrumentalidade se encontra intimamente ligado aos princípios processuais constitucionais do devido processo legal, da razoável duração do processo e do acesso à justiça e, consequentemente aos direitos fundamentais constitucionais, principalmente o da Dignidade da Pessoa Humana.

\footnotetext{
${ }^{61}$ BRASIL. Superior Tribunal de Justiça. Terceira turma. Agravo Regimental no Agravo de Instrumento n. 678474-RJ. Relatora: Ministra Nancy Andrighi. Decisão Unânime. Brasília, 28 nov. 2005, p. 280. Disponível em: <http://www.stj.jus.br/SCON/jurisprudencia/ doc. jsp?livre $=$ instrumentalidade $+\mathrm{do}+$ processo $\& \& b=A C O R \& p=$ true $\& \mathrm{t}=\& \mathrm{l}=10 \& \mathrm{i}=300>$. Acesso em: 22 abr. 2009.
} 


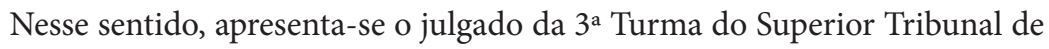
Justiça, que, segundo o relator ministro Humberto Gomes de Barros, constitui "essência da instrumentalidade o máximo aproveitamento do processo, desde que não haja prejuízo às partes," ou seja, o ato processual é considerado válido desde que alcance suas finalidades sociais, políticas ou jurídica, já que, em tese, quando atinge o resultado pretendido, o ato não terá causado prejuízo a nenhuma das partes.

AgRg no REsp 779727 / DF. AGRAVO REGIMENTAL NO RECURSO ESPECIAL. 2005/0148849-5. AGRAVO REGIMENTAL. RECURSO ESPECIAL. JULGAMENTO EXTRAPETITA.INEXISTÊNCIA.INSTRUMENTALIDADE. APROVEITAMENTO DO PROCESSO. 1. Se a providência determinada pelo juiz não depende de pedido das partes, não há Julgamento extra petita. 2. É da essência da instrumentalidade o máximo aproveitamento do processo, desde que não haja prejuízo às partes. ${ }^{62}$

Da mesma forma se apresenta o julgado da $1^{\text {a }}$ Turma do Superior Tribunal de Justiça, que teve como relatora a Ministra Denise Arruda e, segundo o qual, ao mencionar texto de outro julgado, afirma que "a instrumentalidade do processo e o perfil deste no direito contemporâneo não permitem que meras irregularidades constituam impeço à satisfação da prestação jurisdicional".

AgRg no Ag 839381 / RJ. AGRAVO REGIMENTAL NO AGRAVO DE INSTRUMENTO. 2006/02554928. PROCESSUAL CIVIL. NULIDADE DO AUTO DE PENHORA. VALOR INCORRETO. AUSÊNCIA DE PREJUÍZO. 1. "A instrumentalidade do processo e o perfil deste no direito contemporâneo não permitem que meras irregularidades constituam empeço à satisfação da prestação jurisdicional" (REsp 175.546/RS, 4a Turma, Rel. Min. Sálvio de Figueiredo Teixeira, DJ de 13.9.1999). 2. Não verificado nenhum tipo de prejuízo à parte, decorrente de erro no preenchimento do valor do auto de penhora, não

${ }^{62}$ BRASIL. Superior Tribunal de Justiça. Terceira turma. Agravo Regimental no Recurso Especial n. 779727-DF. Relator: Ministro Humberto Gomes de Barros. Decisão Unânime. Brasília, 14 dez. 2007, p. 400. Disponível em: <http://www.stj.gov.br/SCON/jurisprudencia/doc.jsp?livre $=$ instrumentalidade + do + processo $\& \& b=A C O R \& p=$ true $\& \mathrm{t}=\& \mathrm{l}=10$ $\& \mathrm{i}=70>$. Acesso em: 17 abr 2009. 
há falar em nulidade do processo executivo. 3. Agravo regimental desprovido. ${ }^{63}$

Desse modo, a aplicação do princípio da instrumentalidade do processo pelo Superior Tribunal de Justiça, a fim de conferir uma pacificação social justa aos conflitos existentes na sociedade e dessa forma atingir um Estado Democrático de Direito com a participação ativa de todos aqueles que o compõem, vai de encontro ao posicionamento proposto na presente pesquisa, bem como reflete o posicionamento da doutrina majoritária.

Denota-se que, apesar de ter citado somente três jurisprudências do STF, elas servem para ilustrar que, atualmente, já há uma tendência para instrumentalidade do processo no campo jurisdicional e que sua utilização busca encontrar uma forma mais justa e célere para que possa alcançar a pacificação social almejada.

\section{Conclusão}

O trabalho ora realizado escolheu como objeto de estudo o processo, bem como a sua função no Estado Democrático de Direito. Por meio da presente pesquisa podemos observar que o processo possui um papel extremamente importante no âmbito do Estado Democrático de Direito, na medida em que funciona como ferramenta para se atingir a paz social almejada por todos, inclusive pelo próprio Estado enquanto Poder Público. Assim, por meio da solução pacífica dos litígios que existem entre os membros de uma dada sociedade, o processo figura como instrumento para se alcançar o fim pretendido, qual seja, o bem comum assim entendido como sendo a paz social.

Constatou-se que o processo é meio de transformação do campo legal, o que inclui a esfera constitucional, pois as decisões que emanam do Poder Judici-

\footnotetext{
${ }^{63}$ BRASIL. Superior Tribunal de Justiça. Primeira Turma. Agravo Regimental no Agravo de Instrumento n. 839381-RJ. Relatora: Ministra Denise Arruda. Decisão Unânime. Brasília, 31 maio 2007, p. 372. Disponível em: <http://www.stj.jus.br/SCON/jurisprudencia/doc. jsp?livre $=$ instrumentalidade $+\mathrm{do}+$ processo $\& \& b=\mathrm{ACOR} \& \mathrm{p}=$ true $\& \mathrm{t}=\& \mathrm{l}=10 \& \mathrm{i}=164>$. Acesso em: 22 abr. 2009.
} 
ário influenciam tanto no conteúdo da norma, como na sua interpretação. Dessa forma, o processo e a decisões que dele resultam procuram cessar com as lacunas, com as omissões, bem como com a deficiência de linguagem presentes na norma jurídica, por isso dizer que a Constituição e o processo, juntamente com poder desempenhado pelo juiz enquanto julgador são elementos que interagem entre si, ou seja, a interpretação vinda dos tribunais vem sendo apontada como ferramenta de modificação constitucional e infraconstitucional, na medida em que pode motivar pressões no legislador a fim de transformar textos positivados, assumindo um elo entre Constituição e processo, entre o Estado e a sociedade, mesmo que tais decisões não sejam fontes normativas ou fontes que constituam direitos.

Demonstrou-se ainda que o Estado Democrático de Direito faz uso do processo para garantir direitos individuais de liberdade priorizados por essa forma de modelo estatal, pois, como já destacado, o objetivo maior que se procura atingir é a solução justa e rápida dos conflitos sociais para se alcançar um Estado realmente Democrático e de Direito. Assim, a própria Constituição de 1988 estabeleceu, dentre outros, o Fundamento da Dignidade da Pessoa Humana e o Princípio do Devido Processo Legal que norteiam e asseguram o direito a um processo justo, célere, igualitário, para que a ordem e a paz sejam alcançadas e mantidas e, desse modo, o Estado cumpra com a finalidade para a qual foi criado.

No entanto, o processo, dentro desse Estado, para efetivar as garantias constitucionais previstas na Constituição Federal, e assim ser classificado como seu instrumento, precisa estar pautado na justiça a fim de atingir a paz social almejada. Contudo, o referido objetivo somente será alcançado por meio da garantia de acesso à justiça e do respeito aos fundamentos e aos princípios constitucionais.

Observou-se também o posicionamento do Superior Tribunal de Justiça frente à questão da instrumentalidade do processo e se concluiu que a sua aplicação pela justiça pátria encontra conformidade com as ideias constantes na presente pesquisa, pois, como já abordado, o objetivo visado pelo Estado por meio do processo é a solução justa e rápida dos conflitos, para então se obter um Estado realmente Democrático e de Direito. 
$\mathrm{O}$ processo como instrumento deve se adaptar às realidades sociais e às exigências de um dado momento histórico. E se pode não ser tão fácil desvendar os motivos da demanda por tutelas realmente efetivas, é inegável que o atual momento histórico tem reclamado do processo, meios capazes de socorrer adequadamente o autor que mereça proteção. A própria acumulação crescente do número de processos indica a necessidade de proteção jurisdicional concreta.

Por fim, ficou claro que, considerar o processo como instrumento do Estado Democrático de Direito, subentende que ele atinja os escopos sociais, políticos e jurídico, , objetivando assim uma democracia efetiva, ou seja, entender o processo como instrumento do Estado Democrático de Direito é entendê-lo como sendo a própria garantia de acesso a este Estado, pois a concepção de Estado Democrático de Direito, em termos de processo judicial, vai além da proteção da tutela jurisdicional por meio de justiça e rápida solução de conflitos. A reunião desses requisitos, além do respeito à justiça, a duração razoável para se chegar à decisão final, a dignidade daqueles envolvidos na pretensão buscada, enfim, é a forma de entender que o processo e seu devido acesso dentro da legalidade e da licitude tenham como finalidade suprir as angústias presentes na sociedade.

\section{The process as a tool of the democratic state of law}

\section{Abstract}

This present research has as a goal the study of the process as a tool for the Democratic Law State; we tried to attempt the relation this juridical institute to the State model adopted by the new juridical order which began through the 1988 Federal Constitution. This way, on its first article, the Federal Constitution consists of the Brazilian Federative Republic on its Democratic Law State, concerned with an appropriated state organization and with a fair, juridical and rapid lawsuit, as well as affective. The process plays an extremely important role, which is to solve conflicts and bring peace to society by the time it creates laws referring to interpersonal relations through decisions that would come from Courts. The article consecrated by the Constitution also reflects the importance of the constitutional 
basis about human dignity and the constitutional principle on the Due Process of Law, which must be observed by the process, once they work as the structure to the construction of the State proposed by the constitutional institute. The mentioned State must be committed to the social, political and juridical values, which must also be observed through process as an able instrument to reach goals towards public well-being. Summarizing, the research tries to focus the necessary paths to reach effectiveness on the state model proposed by the legislators through analyzing the process as a tool, as it is seen: an element which became part of Justice.

Keywords: Process. Democratic law state. Tool.

\section{Referências}

BEDAQUE, José Roberto dos Santos. Efetividade do processo e a técnica processual. São Paulo: Malheiros, 2006.

BRASIL. Constituição (1988). Emenda Constitucional número 42, de 19 de dezembro 2003. Constituição da República Federativa do Brasil . 33. ed. São Paulo: Saraiva, 2004.

BRASIL. Superior Tribunal de Justiça. Primeira turma. Agravo Regimental no Agravo de Instrumento n. 839381-RJ. Relatora: Ministra Denise Arruda. Decisão Unânime. Brasília, 31 maio 2007, p. 372. Disponível em: <http://www.stj.jus.br/ $\mathrm{SCON} /$ jurisprudencia/doc.jsp?livre $=$ instrumentalidade $+\mathrm{do}+$ processo $\& \& \mathrm{~b}=\mathrm{ACO}$

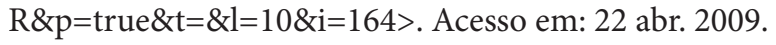

BRASIL. Superior Tribunal de Justiça. Terceira turma. Agravo Regimental no Agravo de Instrumento n. 678474-RJ. Relatora: Ministra Nancy Andrighi. Decisão Unânime. Brasília, 28 nov. 2005, p. 280. Disponível em: <http://www.stj.jus.br/ $\mathrm{SCON} /$ jurisprudencia/doc.jsp?livre $=$ instrumentalidade $+\mathrm{do}+$ processo $\& \& \mathrm{~b}=\mathrm{ACO}$ $\mathrm{R} \& \mathrm{p}=$ true $\& \mathrm{t}=\& \mathrm{l}=10 \& \mathrm{i}=300>$. Acesso em: $22 \mathrm{abr} .2009$.

BRASIL. Superior Tribunal de Justiça. Terceira turma. Agravo Regimental no Recurso Especial n. 779727-DF. Relator: Ministro Humberto Gomes de Barros. Decisão Unânime. Brasília, 14 dez. 2007, p. 400. Disponível em: <http://www.stj. gov.br/SCON/jurisprudencia/doc.jsp?livre $=$ instrumentalidade + do + processo $\& \& b$ $=A C O R \& p=$ true $\& \mathrm{t}=\& \mathrm{l}=10 \& \mathrm{i}=70>$. Acesso em: $17 \mathrm{abr} 2009$. 
CAMBI, Eduardo. Neoconstitucionalismo e neoprocessualismo. Disponível em: $<$ http://www.panoptica.org/fevereiro2007pdf/1Neoconstitucionalismoeneoproces sualismo.pdf>. Acesso em: 19 nov. 2008.

CINTRA, Antonio Carlos de Araújo; GRINOVER, Ada Pellegrini; DINAMARCO, Cândido Rangel Dinamarco. Teoria geral do processo. 19. ed. São Paulo: Malheiros, 2003.

DANTAS, Francisco Wildo Lacerda. Jurisdição, ação (defesa) e processo. São Paulo: Dialética, 1997.

DINAMARCO, Cândido Rangel. A instrumentalidade do processo. 6. ed. São Paulo: Malheiros, 1998.

FIORILLO, Celso Antônio Pacheco. Princípios do processo ambiental. São Paulo: Saraiva, 2004.

GONÇALVES, Marcus Vinicíos Rios. Novo curso de direito processual civil. São Paulo: Saraiva, 2004. v. 1

LENZA, Pedro. Direito constitucional esquematizado. 7. ed., rev. atual. e ampl. São Paulo: Método, 2004.

MACHADO, Fábio Cardoso. Sobre o escopo jurídico do processo: o problema da tutela dos direitos. Jus Navigandi, Teresina, v. 8, n. 343, 15 jun. 2004. Disponível em: <http://jus2.uol.com.br/doutrina/texto.asp?id=5330>. Acesso em: 04 jun. 2010. Acesso em: 19 nov. 2008.

MARINONI, Luiz Guilherme. Teoria geral do processo. 3. ed., rev. e atual. São Paulo: Revista dos Tribunais, 2008.

MELLO, Celso Antonio Bandeira de. Curso de direito administrativo. 8. ed. São Paulo: Malheiros, 1996.

MORAES, Alexandre de Moraes. Direito constitucional. 15. ed. São Paulo: Atlas, 2004.

MOREIRA, Edson Fábio Garutti. Humanismo de Maritain e a burocracia. São Paulo: Loyola, 2001.

NERY JUNIOR, Nelson. Princípios do processo civil na Constituição Federal. 3. ed., rev. São Paulo: Revista dos Tribunais, 1996. 
PASSOS, Calmon J. J. Direito, poder, justiça e processo. Rio de Janeiro: Forense, 2000.

PINTO, Felipe Martins. O princípio do contraditório sob a égide do Estado Democrático de Direito. Disponível em: <http://www.pontojuridico.com/modules. php ? name $=$ News \&file $=$ article $\& \operatorname{sid}=86 \&$ mode $=$ thread \&order $=0 \&$ thold $=0>$. Acesso em: 06 nov. 2008.

OLIVEIRA, Suzana J. de. A função judicante do Estado e a real utilidade do instrumento processual. Disponível em: <http://br.monografias.com/trabalhos909/ a-funcao-judicante/a-funcao-judicante.shtml>. Acesso em: 06 nov. 2008.

SILVA, Enio Moraes da. O Estado democrático de direito. Disponível em: <http:// gravatai2ulbra.tche.br/portal2007/cursos/graduacao/direito/professores/analucia-jaque-ramos/disciplinas/competencia-politica-social-juridica/Estado\%20 Democratico\%20de\%20Direito. pdf>. Acesso em: 08 nov. 2008.

SILVA, Ovídio Araújo Baptista da. Processo e ideologia: o paradigma racionalista. Rio de Janeiro: Forense, 2004.

THEODORO JUNIOR, Humberto. Curso de direito processual civil. 38. ed. Rio de Janeiro: Forense, 2002. v. 1. 
